\title{
Inflection points and industry change: Was Andy Grove right after all?
}

\author{
Fred Phillips $\dagger$ \\ Yuan Ze University, Taoyuan, Taiwan, and CENTRUM Católica, the Business Center \\ of the Pontificia Universidad Católica del Perú, Lima, Peru. \\ G. George Hwang \\ Department of Economics, Shih Hsin University, Taipei City, Taiwan. \\ Pornpimol Limprayoon \\ †Tecnológico de Monterey, Saltillo, Mexico.
}

\begin{abstract}
We examine whether the 'strategic inflection points' described by former Intel CEO Andy Grove correspond to mathematical inflection points in the product/technology life cycle. We find one sense in which they do and two senses in which they do not. This leads to a mapping of colloquial uses of inflection point, tipping point, volatility, chaos, and turbulence against the scientific definitions of these terms. The mapping should be of use to researchers and educators, and also suggests to managers that the possibility of foresight and control in technology-dependent industries is more sharply limited than generally believed. The paper highlights implications for organizational sustainability and offers possible coping mechanisms for managers and directions for educators and researchers.
\end{abstract}

Keywords: Inflection points; resistance to change; technology forecasting; innovation adoption; change management.

\section{INTRODUCTION}

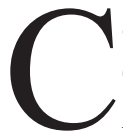

alculus students, who know the inflection point in an s-shaped growth curve is where things start to slow down, would have been confused by Andy Grove's use of 'strategic inflection point' to mean 'the nightmare moment... when massive change occurs and a company must, virtually overnight, adapt or fall by the wayside' (Phillips, 2007).

Two points jump from the inset above: First, there is confusion about the term 'inflection point,' and second, such points - at least in Grove's definition - are substantial threats to the enterprise's sustainability. The first reaction to a 'nightmare moment,' according to Laakso et al. (2013) is to ensure all parties share a common vocabulary for dealing with it.

We therefore begin this paper by addressing and clarifying the terminology of instability in technology businesses. In so doing, we bring together diverse literature, a mathematical derivation, and short cases to show that the "middle" portion of a technology/product diffusion cycle is not the predictable domain that earlier literature had implied. Recent research, as well as our analysis and

Journal of Technology Management for Growing Economies Vol. 7, No. 1 April 2016 pp. 7-26

\section{CHITKARA 司 UNIVERSITY}

(C)2016 by Chitkara University. All Rights Reserved. 
Phillips $\dagger$, F.

Hwang, G. G. Limprayoon $\dagger$, P.

our original case, shows that waves of product revitalizations, plus chaotic or quasi-chaotic transitions, result in alternating periods of stability and instability. From this finding and from our clarification of terms, we are able to draw recommendations for managers and educators.

In the sections that follow, we explore Grove's idea of inflection points, comparing them to 'tipping points' and to mathematical inflection points in the product/technology life cycle, and examining their relationship to product revitalization and technological substitution. We discuss other terms that imply technology and business discontinuities, such as turbulence and disruption. We summarize a few of Grove's industry examples, adding a short illustrative case of our own. Managerial implications of this investigation are explored, as are implications for teachers and researchers.

We suggest measures to recognise the onset of chaos before it is too late, and suggest that marketing strategists develop a new attitude about volatility. The expected alternation of smooth growth and chaos, and the different management styles needed to deal with the two regimes, suggest that (despite the obvious organizational difficulties in doing so) companies should consider tag-teaming managers over the lifetime of a product line.

\section{DIFFUSION AND CHAOS}

The literature of technology diffusion and market growth has maintained that while deterministic chaos may occur at the beginning or 'end' of an s-shaped market growth curve, the middle section is stable and predictable (Modis and Debecker, 1992, Linstone, 1999). Kelly's (1995) description is clear:

"Growth is extremely sensitive to initial conditions; the first data points on a growth curve are almost meaningless. But once a phenomenon is on a roll... one can extract from the curve a cross-over point with a competing system, or a 'ceiling' and a date when the ceiling essentially flattens out. If such growing systems are examined at the right time (midway in their history), then the presence of local order-summed up by the S-curve law-affords [a] pocket of predictability."

Thus it was puzzling when former Intel CEO Andy Grove, in his book Only the Paranoid Survive, characterised the challenging, make-or-break moments of a company's history as 'inflection points' (Grove, 1996a, 1996b). Because the inflection point of a symmetric logistic or Bass (1969) growth curve is in the stable region, one would expect these challenging moments to occur near the start-up of growth, or near saturation or maturity, when technological substitutes start to enter the scene. That is, not at the mathematical inflection point of the s-curve, where its second derivative changes sign (see Figure 1). Did Grove, an engineer, use the term 'inflection point' for rhetorical color,

Journal of Technology Management for Growing Economies, Volume 7, Number 1, April 2016 
rather than for mathematical precision? Why does the question matter?

Subsequent writers have used related scientific terms - disruption, tipping points, chaos, etc. - in ways that are informal or metaphorical, diverging from earlier definitions in the hard sciences and engineering. This paper reviews these usages that address aspects of business and technological instability, bringing them together "under one roof," characterising and clarifying them, and finally summarizing them in Table 1.

Followers of chaos theory will recall that prediction and control are impossible once a trajectory has entered a chaotic regime. Whereas Phillips (2007) mined the Bass equation for evidence of the best time to stop advertising, we now look at the increased advertising and promotion pulses that underlie product revitalization initiatives, and their dangers. Our development of the structural similarity of product revitalization and technological substitution - added to evidence from the literature - implies that chaos may arise in managerial situations more frequently than has been realised heretofore. It is now clear that a revitalization attempt can lead to uncontrollable fluctuations, making it possibly more risky than refraining from attempted revitalization. Modis and Debecker's (1992) implication that 'The generalised picture [of market evolution] is one of alternating states of logistic growth and chaos' is consistent with Grove's observations.

\section{GROVE'S STRATEGIC INFLECTION POINTS}

Grove popularised the expression 'inflection point' as a business term. Mathematically, an inflection point is a point on a curve at which the tangent crosses the curve itself. Grove defines inflection point as a strategic point in the life of a business or project when its fundamentals are changing significantly. 'Point' is really a misnomer because it may be a long, sometimes painful period of change. In business terms, it means something new is happening and there's no going back; no more 'business as usual'.

In Grove's (1996b) words: Strategic inflection points can be caused by technological change but they are more than technological change... They are full-scale changes in the way business is conducted, so that simply adopting new technology or fighting the competition as you used to may be insufficient. They build up force so insidiously that you may have a hard time even putting a finger on what has changed, yet you know that something has. Let's not mince words: A strategic inflection point can be deadly when unattended to.

Strategic inflection points do not always result in catastrophe. Strategic inflection points can be opportunities for businesses that prepare and possess

Journal of Technology Management for Growing Economies, Volume 7, Number 1, April 2016
Inflection Points and Industry Change 
Phillips $†$, F. Hwang, G. G. Limprayoon $\dagger$, P. skills for dealing with the new changes. This may mean opportunities for a new period of growth. Grove affirms that any businesses can be both the subject of and the cause of a strategic inflection point; he believes Intel has been both.

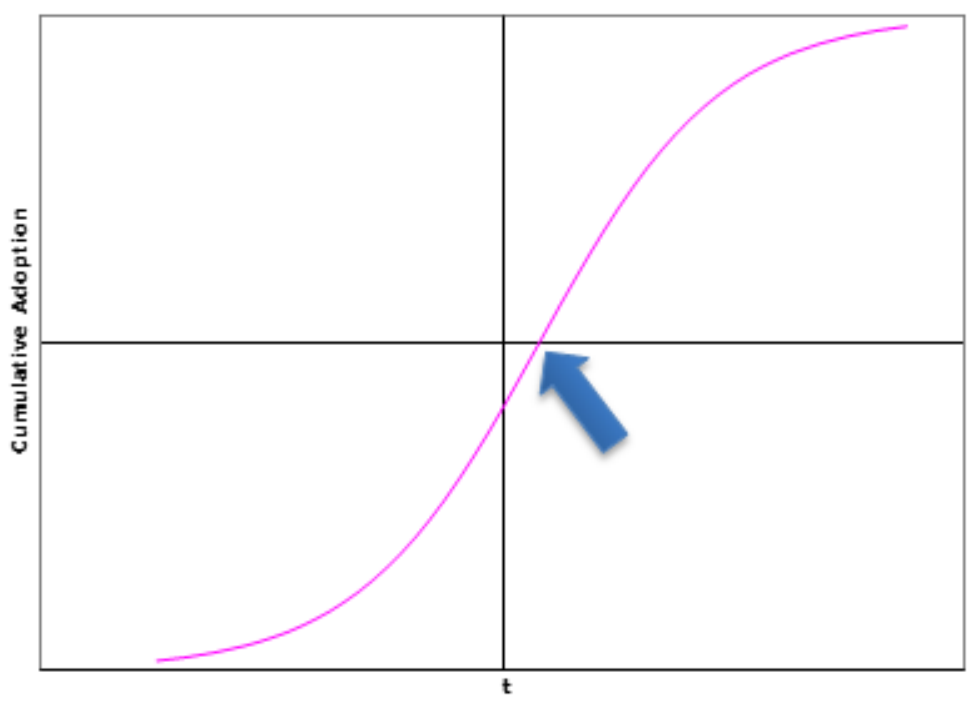

Figure 1: At the inflection point, an s-curve shifts from convex to concave Grove suggested that the IT (information technology) industry was on the cusp of a new inflection point in 1996. 'We live,' he wrote then, 'in an age in which the pace of technological change is pulsating ever faster, causing waves that spread outward toward all industries' (Grove, 1996b). This change has had huge impacts and will bring new competition from new ways of living and doing businesses.

\section{INFLECTION POINT AS TIPPING POINT}

Gladwell (2000) 'tipping point' idea enriched the question somewhat. Phillips (2007) showed (following Modis (2002)) that logistic curves have no tipping points, but that the Bass model can be interpreted in a way that manifests a tipping point early in the life of the growth curve, though this tipping point is far from the inflection point. Phillips (2007) went on to introduce an extension of the Bass model incorporating resistance to change:

$$
\mathrm{X}_{\mathrm{t}+1}-\mathrm{X}_{\mathrm{t}}=\left[\mathrm{p}\left(1-\mathrm{r}+\mathrm{rX} \mathrm{t}_{\mathrm{t}}\right)+\mathrm{qX}_{\mathrm{t}}\left(1-\mathrm{r}+\mathrm{r} \mathrm{X}_{\mathrm{t}}\right)\right]\left[1-\mathrm{X}_{\mathrm{t}}\right]
$$

In this 'advertising-imitation-resistance' or AIR model, $X_{t}$ is the proportion of potential adopters who have adopted at time t. $\mathrm{p}$ is a coefficient of positive 
external influence, $r$ a coefficient of negative influence (resistance to the change), and $\mathrm{q}$ a coefficient of positive internal influence. The AIR curve is s-shaped and monotonically increasing for $0<r<1$. It reduces to the Bass model when $r=0$.

This new three-parameter model, having richer 'intricate structure' than the logistic, Bass, or Fourt and Woodlock (1960) curves, evinces a greater number of tipping points. One of these is the point at which the number of potential imitators who are dissuaded by resistance to change reaches a peak and then declines. Though Phillips (2007) specified this point, he neglected to factor a difference-ofsquares term in the formula for its location.

When we factor the term, we see the tipping point occurring when the adopting fractions $X_{t}+X_{t+1}>1$ for the first time. (We refer to the normalised version of the s-curve, for which the 'total market potential' or 'total potential adopters' is set to unity or $100 \%$.) This condition can hold only when both $\mathrm{X}_{\mathrm{t}}$ and $\mathrm{X}_{\mathrm{t}+1}$ exceed 0.5 , or when $X_{t+1}$ exceeds 0.5 by a margin that makes up for the amount by which $X_{t}$ falls short of 0.5 . That is, this tipping point occurs at or near the inflection point.

Most diffusion literature (inter alia, Rai et al. (1998) and Kelly (1995)) says the greatest uncertainty occurs at the product launch, or at the late maturity when the product is threatened by more advanced substitutes. The middle, they say, is stable and predictable. Boswijk and Franses's (2005) observation that the beginning and the end of a product life cycle are characterized, by definition, by zero sales, is a viewpoint on the opposite extreme. The middle of the cycle, they reasoned, perforce entails more uncertainty than the beginning or the end. Our result agrees to a greater extent with that of Loch and Huberman (1999), who maintain that uncertainty is evinced throughout the diffusion cycle start, end, and middle.

The same finding compelled us to take another look at Grove's terminology. Phillips (2007) had shown that an important battle, between proponents of an innovation and those resisting it, is won or lost at the inflection point. Grove wrote about companies operating in a competitive environment - companies working against each other - and this could be seen as one company's growth being 'resisted' by competitive pressures. In this sense, Grove was correct that a serious challenge is overcome at an inflection point.

\section{PRODUCT REVITALIZATION: A STRATEGIC INFLECTION POINT?}

One of Groves' illustrations refers to another point in a product line's life cycle, one that is not a 'natural' part of the s-curve. See Figure 2.

Marketers call the line on the upper right of Figure 2 'product revitalization'. A common concept in many publications since Levitt's (1965) article, revitalization can result from exploitation of new market niches or new distribution channels; new technologies that expand the product's capabilities; finding new uses for the product; or from creating and observing new industry standards. When the re-
Inflection Points and Industry Change

Journal of Technology Management for Growing Economies, Volume 7, Number 1, April 2016 
Phillips $\dagger, \mathrm{F}$. Hwang, G. G. Limprayoon $\dagger$, P. vitalization point is conceptualised as an inflection point, the result is the inverted s-curve of Figure 2.

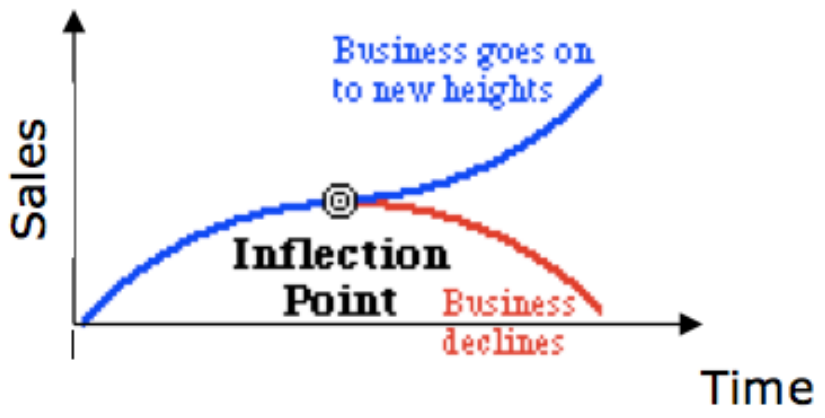

Figure 2: A life cycle curve with an inflection point indicating the success (top curve) or failure (bottom curve) of a product revitalization. Adapted from Grove (1996a).

Revitalization can be motivated by internal factors - in-house innovations, understanding that the current product is reaching maturity, wishing to "cross the chasm' (Moore, 2002) from the innovator market to the mass market - or by external competitive pressure. Sood and Tellis (2004) analyzing twenty-three technologies across six markets, conclude that repeated revitalizations (plateaux followed by sharp increases) in the cumulative adoption curve are the norm, and that the classical s-curve is rarely seen in technology markets in its pure and uninterrupted form. The marketing challenge of a product revitalization can be substantial. At first take-off, the product may represent a new-to-the-world product category. Any second, post-maturity take-off is within a now-familiar product category, requiring quite different marketing skills.

The lower curve in Figure 2 is a product life-cycle curve. PLC curves are usually represented as the derivative of the s-curve of cumulative sales or adoption. However, perhaps for simplicity of presentation, Grove (1996b) (like Fourt and Woodlock (1960), whose model has no coefficient of internal influence) uses an arc that lacks the inflection point of the logistic, AIR, or Bass s-curve. (Figure 3 shows both inflection points.)

Instead, Figure 2 emphasises the inflection point that can result when a product is revitalised. This inflection point is not an inherent or 'natural' part of a growth phenomenon. It is deliberately created by the firm that successfully revitalises its product line. Grove uses the term especially for revitalizations that result from extreme competitive pressure; that is, not so much revitalization as survival and viability following an existential threat.

Figure 3 makes this distinction clear. Figure 4 shows a numerical calculation 
of revitalization based on increasing the coefficient of positive external influence (i.e., sharply bumping up the advertising budget) at 'period 25'. This is shown as the upper curve in the Figure; the lower curve shows the natural decline of the product's sales life in the absence of a revitalization. In Figure 4, the revitalization is not a mathematical inflection point. Additionally, it is a simplistic representation that ignores technological substitution and the possibility of chaotic transition.

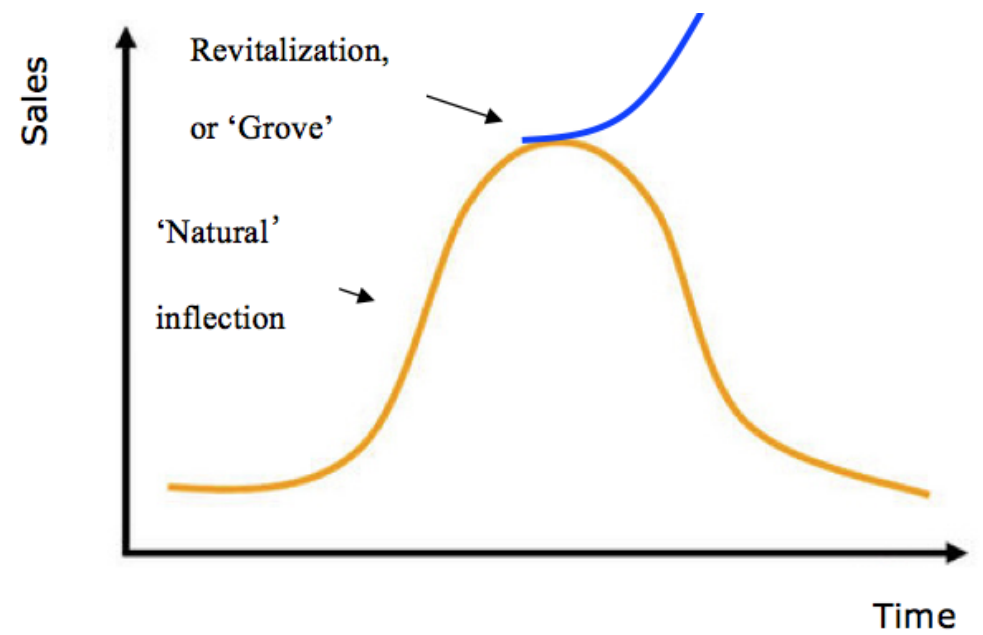

Figure 3: Life cycle curve with product revitalization

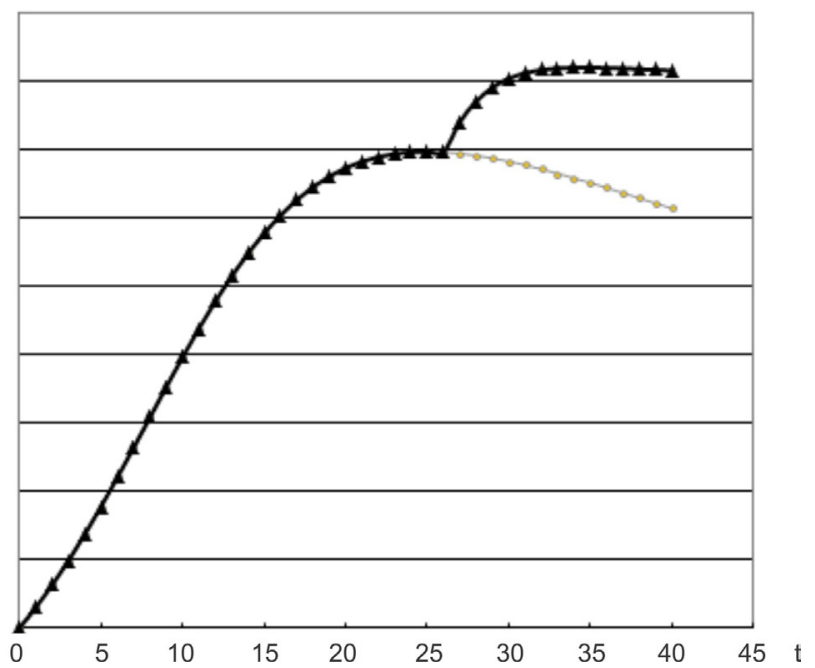

Figure 4: Numerical illustration of product revitalization, based on AIR model, with advertising effect ( $p$ parameter) increasing at period 25. Lowerright curve (circles) show life-cycle alternative to revitalization.

Journal of Technology Management for Growing Economies, Volume 7, Number 1, April 2016
Inflection Points and Industry Change 


\section{Phillips $\dagger$, F. MODIS-DEBECKER VOLATILITY}

Hwang, G. G. Limprayoon $\dagger$, P.

We wrote that Grove 'conceptualised' the revitalization as an inflection point. The fact is that it might not be an inflection point. Modis and Debecker (1992) showed the graph (Figure 5) of bituminous coal production in the United States, with successive logistic curves fitted, representing the opening of a new market niche for the mineral just before mid-century. It is a good illustration of their thesis that 'chaos-like states can be expected before and after logistic growth,' and of Drucker's (1968) prescient idea of industrial 'discontinuities.'

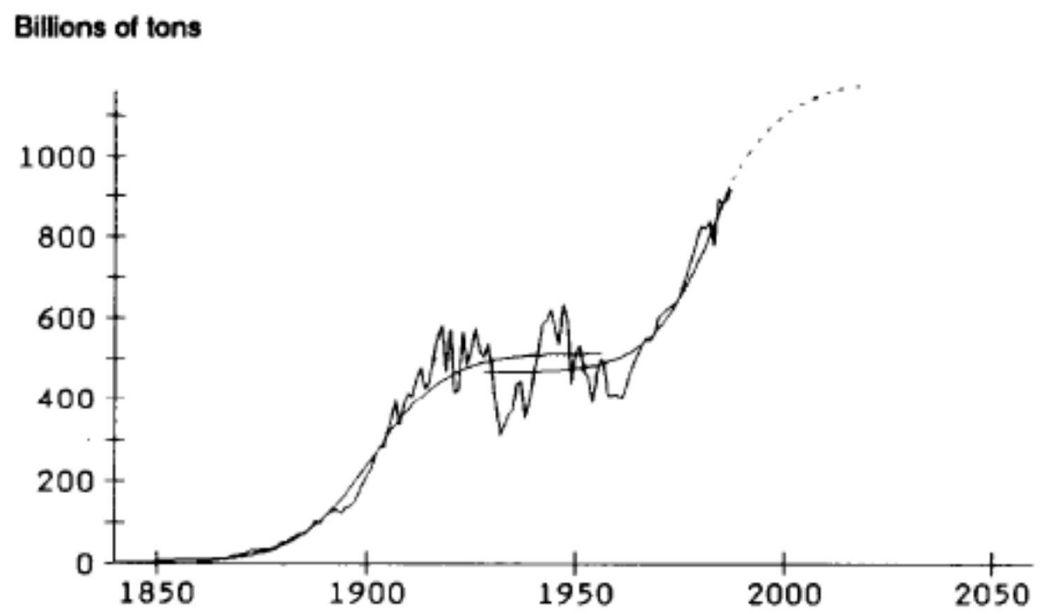

Figure 5: Chaos-like transition from saturation of one market segment and initial growth of a new segment. From Modis and Debecker (1992).

The chaos-like states of Modis and Debecker (1992) are generated by certain parameter values of an iterated discrete version of the logistic curve. (True chaos arises mathematically from continuous functional forms.) They note, 'Our approach... does not lead to true chaos. The oscillations we observe die out sooner or later... Consequently, our series is a reversible one; from late values, one can reconstruct early ones, which is not the case with true chaos' (Modis and Debecker, 1992)

Modis and Debecker (1992) also reproduce a graph of Ausubel et al. (1988) showing the same effect for worldwide per capita annual energy consumption. This quasi-chaos may show itself at the end of a logistic growth cycle, but not in the middle. Interestingly, this data series appears to capture the 'precursor' false jump at the early launch phase, often seen as a result of channel-loading, marketing hype, or the early tipping point of the Bass and AIR models in which imitation effects are about to outstrip advertising effects, and producers cut back on ad expenditure. This particular instance of quasi-

Journal of Technology Management for Growing Economies, Volume 7, Number 1, April 2016 
chaos seems to capture as well as the 'overshoot' in the late cycle which may be caused by hoarding of an item which is expected to be removed from the market. Modis and Debecker (1992) remark, 'The chaotic fluctuations belong to the end of [one] growth phase as much as to the beginning of the next one.... Associating a peak with the past as an overshoot, or with the future as a precursor, is in some cases a simple question of taste.'

Thus a chaotic or quasi-chaotic transition between market niches (a revitalization) may appear to be an inflection point because the process is observed and recorded at discrete intervals, potentially disguising the chaotic fluctuations (Phillips and Kim, 1996). As Modis and Debecker (1992) put it, 'The line appears smooth because of rapid sampling.'

\section{TECHNOLOGICAL SUBSTITUTION}

Though technology substitution is usually pictured as an $\mathrm{x}$-shaped crossing of two mirror-image s-curves representing market share (Fisher and Pry, 1971), substitution is sometimes portrayed as successive s-curves as in Figure 6. Figures 5 and 6 differ in that Figure 5 shows a revitalization (opening of new markets) leading to increased sales (shown on the vertical axis), and Figure 6 shows on its vertical axis improved product performance due to technological advance.

\section{Search Engine Ad Formats}

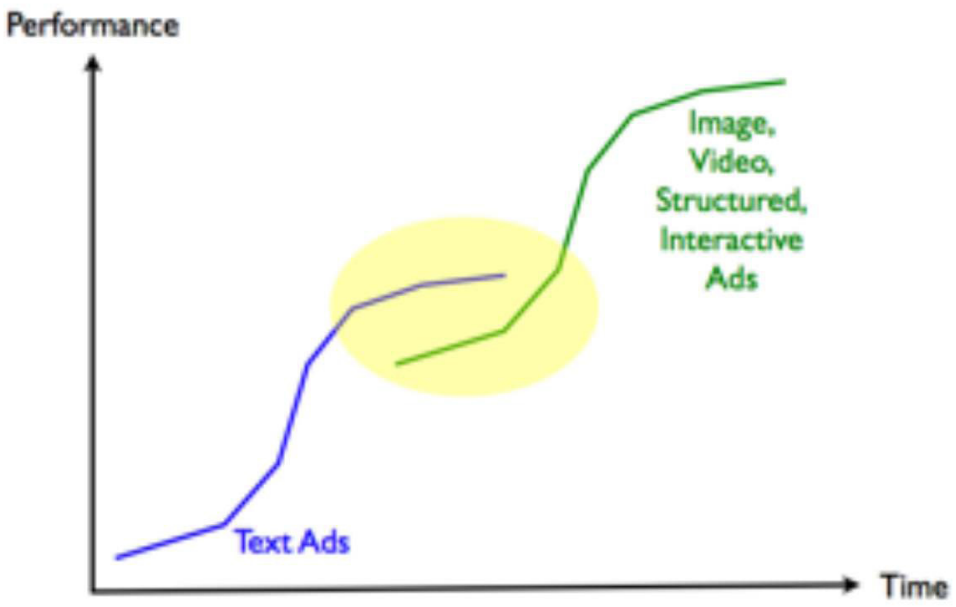

Figure 6: Technological substitution represented as successive s-curves

(Brinker, 2008).
Inflection Points and Industry Change 
Phillips $\dagger$, F.

Hwang, G. G. Limprayoon†, P.

The implication of Figure 6 is that the enhanced performance/cost ratio of the new technology will enlarge the potential market. (The Fisher-Pry model does not explicitly show total market growth, but does not rule it out.) However, the area in the shaded oval represents the end of one growth curve and the start of another, just as in Figure 5. It suggests, correctly, that chaos is possible. In a similar diagram, Dimov et al. (2008) label this region 'disruption'. See also Christensen (1998).

When Company A's product line depends on a mature technology, and competitor Company B's product line depends on a newer and innovative technology, the technology substitution process poses a strategic threat to Company A. To remain viable, A must upgrade. Thus a new, substituting technology may represent a singular strategic challenge for an incumbent firm - a 'chaotic transition' in both the technical and vernacular senses - but not a true inflection point. This was certainly the case with the successive generations of microprocessors produced by Intel and its competitors.

\section{TURBULENCE AND DISRUPTION}

Both Drucker (1993) and Ansoff and McDonnell (1990); see also Seet (2005) used the word turbulence to describe non-stable business environments, and Ansoff constructed a subjective rating scale for environmental turbulence. Thus, business use of the term has differed from the original usage of turbulence, in fluid dynamics. Wolfram (2002) avers that fluid turbulence has a component of randomness as well as one of deterministic chaos.

Christensen (1998) noted that many a business has failed due to ignoring 'disruptive technologies.' The disruptive technologies notion is valuable, and pertinent here due to its connection to technology substitution, but is a 'smaller' idea than inflection points because it does not imply sweeping changes in society, industry, technology, and politics. (To the extent that it was a disruptive technology, the substitution of transistors for vacuum tubes came close to causing such sweeping changes, however.) Like Ansoff and McDonnell (1990) and Drucker (1968), Christensen (1998) introduced a new word usage. Christensen (1998) contributes by focusing on the individual and organizational psychology of denial in the face of technological change

Kaplan et al. (2003) using 23 years of data from 15 pharmaceutical firms, showed that senior executives' vision concerning the future importance of biotechnology shaped firms' responses to the revolution in that field. They conclude that 'cognition at the most senior level can play a critical role in shaping established firms' response to discontinuities'.

\section{STRATEGIC INFLECTION POINTS: CASES}

This section summarizes, in a paragraph each, several of Grove's examples

Journal of Technology Management for Growing Economies, Volume 7, Number 1, April 2016 
of 'inflection points,' including Wal-Mart, Apple, and Barnes \& Noble. We add a lengthier case, centered on technological changes in the survey research industry in the 1980s, that brings home the discussion of techno-managerial discontinuities.

Grove (1996a) cites as an example the situation of Wal-Mart entering new markets with its superior logistics system, high technology inventory management system, large-volume-based purchase costs, and systematic companywide training programs. This had a huge impact on small local stores, causing them either to lose business or to find new niches. Accompanying changes in cargo handling and containerization augmented this strategic shift, and created a parallel one in transport industries.

Changes in technology influence customers to change their purchasing behaviour. Grove discusses Barnes \& Noble, the giant book retailer that has had to deal with upstart Internet-based booksellers. At the time, Barnes \& Noble had not only managed to eclipse them in sales but eclipse them in market valuation. Amazon.com then had more than a half billion dollars of revenue and has become the giant of online selling. To survive, Barnes \& Noble have had to change the way they do business; they attempted this by focusing on combined 'bricks and clicks' selling. Grove called this another strategic inflection point in the retail business.

The strategic inflection point in the computing industry was the period that began with the introduction of PCs. Grove writes of Steve Jobs, the late CEO of Apple, who created an extremely successful personal computer company. Another example is the change in the software industry. Grove notes that Microsoft, which entered the business to compete with Apple, caused a massive change in the software industry, ultimately pushing Apple to innovate in business models for the music and telephone industries. The current generation of young people in the United States has been using computers since grammar school and now takes them for granted. That is a significant change that has created more strategic inflection points.

One of us experienced a strategic inflection point while working in the market research industry (Phillips, 2001). Since the 1930s, Market Research Corporation of America (MRCA) had conducted purchase behaviour surveys, and the A.C. Nielsen Company concentrated on media audience measurement. The 1960s saw the mathematical revolution in market research, with new algorithms for predicting brand shifting, purchase frequencies, and other marketing phenomena. The advent of commercial database software in the 1970s made this easier. Laser scanners could now be used to record purchases of an item at a supermarket checkout. On the consumer side, increasing affluence and increasing divorce rates changed the profiles, buying habits, and

Journal of Technology Management for Growing Economies, Volume 7, Number 1, April 2016
Inflection Points and Industry Change

$\longrightarrow$


Phillips $\uparrow$, F.

Hwang, G. G.

Limprayoon $\dagger$, P. survey response rates of US households.

At the time, few stores used checkout scanners. In 1979, Information Resources Inc., aiming to revolutionise consumer surveys, raised enough IPO capital to give scanners to every supermarket in a half-dozen 'pod markets' throughout the US, in return for rights to the checkout data. Nielsen soon followed suit with its own scanner ventures. For the first time, supermarket purchases could be automatically recorded and linked to households with known characteristics. Because this seemed 'objective' and eliminated key-entry tasks, manufacturers were excited about the prospect of more accurate data, and were motivated to shun MRCA's paper-and-pencil data collection methods in favour of the newer services.

At first, they were disappointed. 'Universal' Product Codes (UPCs) did not uniquely identify products. Local pod markets could not produce nationally projectible data. Sample members forgot to take their ID cards to the supermarket. Processing voluminous scanner data was error-prone. Through the mid-1990s, studies reported that up to $9 \%$ of prices shown at the scanner checkout differed from the prices marked on shelves or packages, or were otherwise in error. K-Marts, gas stations and department stores did not own scanners, but sold significant amounts of foods and other fast-moving consumer goods. It took manufacturers several months to see that these problems compromised the actionability of their market research data. They began to re-subscribe to MRCA's service - raising false hopes within MRCA. The scanner survey firms were experiencing a 'hype curve' - the interrupted growth curve so frequently seen in technology industries - while the same events produced a strategic inflection point for MRCA.

Market research companies had always been considered service businesses, using debt financing rather than equity. The idea of venture backing and IPOs was foreign to the industry. MRCA, a privately held company, did not wish to dilute ownership in order to raise capital and risk it in a 'me too' scanner panel offering. MRCA examined its core strengths, and decided to compete not on the basis of data collection technology but on the basis of analysis, reporting, and customer service technology. MRCA introduced the industry's first PC-based consumer panel data analysis and presentation tool (Phillips, 1985), but this was not enough. The scanner survey firms overcame their technical difficulties, and clients again embraced their offerings. Repercussions were felt by both kinds of firms: MRCA is no longer in business, and A.C. Nielsen was swallowed by Dun \& Bradstreet (and later divested, in small pieces).

Technological change, upstart competition, new financing mechanisms, and changing consumer habits conspired to create a strategic inflection point in the market research industry. Initial problems with technical implementation and service design of scanner panels confused customers and created the chaotic fluctuations leading to MRCA's demise and the sale of Nielsen. 
For their part, supermarket chains invested in their own scanners. They used their now-proprietary scanner data to compute the profitability of each foot of shelffacing in every store. This led to the levying of 'slotting allowances', payments from the manufacturers to the store to allow the display of new products. Scanners had shifted power from the manufacturers to the stores - another instance of a strategic inflection in retailing.

\section{SUMMARY AND IMPLICATIONS}

Andrew Grove emphasizes the rapidity of change, citing changes in transportation, retailing, microprocessors, and digital media. Particularly, he says, computerrelated industries are changing, and the macro environment in which they work is also changing, resulting in something new which will win out over the old way of doing business. Grove affirms that a company's existing and potential competitors, how they play, their competence, their funding abilities and their aggressiveness, today and tomorrow, may lead to an inflection point. In addition, Grove sees substitution as the most 'deadly' form of transition point, causing and being caused by new techniques, new approaches, new technologies, new rules and new climates for doing business.

Andrew Grove may well have intended for 'strategic inflection point' to mean something distinct from 'mathematical inflection point'. Nonetheless, the above clarification and analysis are necessary if his expert views are to be folded into management theory.

Moreover, Grove was indisputably (if implicitly) talking about chaos, using the mythical imagery (treks through the wilderness, the resolve of the leader, etc.) traditionally associated with order's battle against chaos. This was an extraordinary thing for Grove to do. If ever there was a company managed 'by the numbers,' Intel, whose business is dominated by Moore's Law, surely has been one. That Grove described something far more multi-dimensional was not grasped by Grove's reviewers at the Decision Sciences Institute or at the American Society for Engineering Education (Ruppel, 1997, Smith, 2009) - perhaps not surprisingly, given the common perception of Intel's by-the-numbers culture - which further justifies highlighting it here.

The research presented here is limited in that it is the authors' considered opinion of the best technical definition of the terms inflection, instability, turbulence, etc. Others may reasonably differ. However, like other engineering disciplines, technology management deserves a uniform terminology, and we hope other researchers will either agree or argue the definitions here. Though we have shown that stability and instability follow each other throughout the product cycle, we are not yet able to specify the timing of these transitions. Though the short cases show the transitions have happened in a number of industries (semiconductors, books, research services), we cannot yet say that they are always to be expected in all of

Journal of Technology Management for Growing Economies, Volume 7, Number 1, April 2016
Inflection Points and Industry Change 
Phillips $\uparrow$, F. these industries. This is grist for future research.

Hwang, G. G.

Limprayoon $\dagger$, P.

\section{SUMMARY OF FINDINGS FOR ENTERPRISE SUSTAINABILITY}

We have distinguished three points of dynamic tension in the life cycle of a product (or product line, technology, or industry): (i) the point at which innovation overcomes resistance to change (the AIR model's tipping point), (ii) the point at which customers or competitors challenge a firm's inertia and spur a product revitalization, and (iii) the substitution of a new technology for a mature technology. Each of these poses a strategic challenge to the firm, but only one is at a true inflection point.

We have drawn the distinction among tipping points, inflection points, points of potential chaos, and other constructs implying instability or discontinuity. See Table 1. We have confirmed that Grove, for the most part, was concerned with periods of chaos and volatility rather than inflection points. They are not the same; a graph of a chaotic regime is not differentiable, and cannot have inflection points. Moreover, at the (mathematical) inflection point of an s-curve, change slows; it does not accelerate as Grove implied.

Modis and Debecker's powerful mathematical and empirical demonstration of the stability of logistic growth in the middle regime (and the potential instability at the extremes), together with Grove's case studies and provocative terminology, show that the smooth revitalization and substitution curves of our textbooks are misleading, mathematically and managerially.

Modis and Debecker (1992) showed that chaos comes from substitution, the phenomenon Grove regards as specially dangerous. It does not generally arise from single-item diffusion, as implied by the earlier writers cited (and in some degree echoed) by Phillips and Kim (1996).

Dynamic tension points (ii) and (iii) above can be chaotic in the true technical sense, and this implies that strategic intent, alertness and flexibility, and luck are needed if the firm is to emerge viably (Phillips and Su, 2009).

Indeed points (ii) and (iii) are structurally similar. Point (i), however, the AIR tipping point, can be monitored and predicted with some confidence.

Due care is called for in drawing correspondences between the math and the situation under study. Is there a reason why the continuous growth curve should better reflect the situational reality than the discrete form, or vice versa? Is it plausible that a parameter may vary or take on an unusual value? Does the situation call for representation via the (derivative) bell-shaped life cycle curve or the (integral) cumulative adoption curve? When the latter curve seems, under some parameter values, to violate monotonicity, is there a legitimate explanation? These questions are answered simply in the particular case of Figure 5 above, where the data seem to fit the theory very well. In other industries, they must be answered on a case-specific basis, recognizing the limits of mathematics and the current undeveloped state of theory.

Journal of Technology Management for Growing Economies, Volume 7, Number 1, April 2016 


\section{Table 1. Map of colloquial/popular usages to technical meanings: Inflection points and related terms}

\begin{tabular}{|c|c|c|}
\hline Term & $\begin{array}{l}\text { Colloquial use in popular } \\
\text { business literature }\end{array}$ & Technical definition in the sciences or engineering \\
\hline $\begin{array}{l}\text { Inflection } \\
\text { point }\end{array}$ & $\begin{array}{l}\text { 'the nightmare moment... } \\
\text { when massive change oc- } \\
\text { curs and a company must, } \\
\text { virtually overnight, adapt or } \\
\text { fall by the wayside' (Grove, } \\
\text { 1996a). }\end{array}$ & $\begin{array}{l}\text { In calculus, a point where the tangent crosses the curve, } \\
\text { i.e., the second derivative equals zero. }\end{array}$ \\
\hline $\begin{array}{l}\text { Tipping } \\
\text { point }\end{array}$ & $\begin{array}{l}\text { 'The moment on the graph } \\
\text { when the line starts to shoot } \\
\text { straight upwards' (Gladwell, } \\
\text { 2000). }\end{array}$ & $\begin{array}{l}\text { In systems theory, a critical threshold. 'Complex systems } \\
\text { can also exist in alternate stable states, in which they be- } \\
\text { have quite differently. The point at which they flip to the } \\
\text { alternate state is the threshold or tipping point. A complex } \\
\text { system in a stable state can be 'flipped' into another stable, } \\
\text { state by a disturbance that pushes it across the threshold.' } \\
\text { (Australian Academy of Science, 2006). The US National } \\
\text { Science Foundation (National Science Foundation Adviso- } \\
\text { ry committee for Environmental Research and Education, } \\
\text { 2009) emphasized that the effect of the disturbance may be } \\
\text { unpredictable. } \\
\text { Gladwell (2000) claimed the term is used in epide- } \\
\text { miology to denote the time at which a virus, passing from } \\
\text { neighbour to neighbour, cannot be prevented from causing } \\
\text { mass contagion. }\end{array}$ \\
\hline Volatility & $\begin{array}{l}\text { Used ubiquitously to sug- } \\
\text { gest rapid growth, decline, } \\
\text { or fluctuation. }\end{array}$ & $\begin{array}{l}\text { In chemistry, 'a chemical's vapor pressure, which is the ba- } \\
\text { sis for its evaporation rate, boiling point and-if the chem- } \\
\text { ical is flammable-its flammability' (Jonas, 2005). } \\
\text { In finance, 'The relative rate at which the price of a } \\
\text { security moves up and down. Volatility is found by calcu- } \\
\text { lating the annualized standard deviation of daily change in } \\
\text { price.' Measured by } \beta \text {, 'a quantitative measure of the vola- } \\
\text { tility of a given stock, mutual fund, or portfolio, relative to } \\
\text { the overall market, usually the S\&P } 500 \text {. Specifically, the } \\
\text { performance the stock, fund or portfolio has experienced in } \\
\text { the last } 5 \text { years as the S\&P moved } 1 \% \text { up or down. A beta } \\
\text { above } 1 \text { is more volatile than the overall market, while a } \\
\text { beta below } 1 \text { is less volatile.' (Source: Investorwords.com) }\end{array}$ \\
\hline Chaos & $\begin{array}{l}\text { Commonly, an antonym of } \\
\text { order. Indicates extreme } \\
\text { unpredictability, uncon- } \\
\text { trolla-bility. May connote } \\
\text { something to be feared. In } \\
\text { a religious context, often } \\
\text { associated with the work of } \\
\text { the devil. }\end{array}$ & $\begin{array}{l}\text { In physics, chemistry, engineering, and systems theory, } \\
\text { (deterministic) chaos denotes an unpredictable trajecto- } \\
\text { ry, the history of which cannot be reconstructed from the } \\
\text { system's current state. Chaos may arise from the iteration } \\
\text { of a function, or from small changes in the initial state of } \\
\text { a system described by a set of differential equations. As } \\
\text { the term deterministic chaos suggests, chaotic trajectories } \\
\text { are not random. (Prigogine, 1984) often spoke of chaotic } \\
\text { 'fluctuations.' }\end{array}$ \\
\hline
\end{tabular}

Inflection Points and Industry Change 
Phillips $\dagger, \mathrm{F}$. Hwang, G. G. Limprayoon $\dagger, \mathrm{P}$.

\begin{tabular}{|c|l|l|}
\hline Term & $\begin{array}{c}\text { Colloquial use in popular } \\
\text { business literature }\end{array}$ & Technical definition in the sciences or engineering \\
\hline Disruption & $\begin{array}{l}\text { 'Generally, disruptive tech- } \\
\text { nologies underperform es- } \\
\text { tablished products in main- } \\
\text { stream markets. But they... }\end{array}$ & $\begin{array}{l}\text { In genetic engineering, a technology that enables muta- } \\
\text { tions to be rapidly generated in a specific gene or genes } \\
\text { (http://www.genengnews.com/articles/chtitem.aspx- } \\
\text { ?tid=1092\&chid=1). }\end{array}$
\end{tabular}

In supply chain management, an interruption in logispler, small ly, more convenient to use' (Christensen, 1998)

\section{tics} eruption.

Dimov et al. (2008) used 'disruption' to describe the (quasi-)chaotic regime between successive growth curves following a product revitalization or substitution.

Christensen (1998) disruption is a special case of technology substitution, characterized by low price and initially limited functionality of the upstart technology.

In fluid dynamics, the 'state of fluid motion [that] arises when the speed of the fluid exceeds a specific threshold, below which viscous forces damp out the chaotic behavior,' characterized by 'patches of zigzagging, often swirling fluid, moving randomly around and about the overall direction of motion (Moin and Kim, 1997)

Turbulent fluid flow, approximated by the Navier-Stokes equations, is contrasted to the more regular 'laminar' flow of viscous fluids. Now thought to combine randomness and deterministic chaos, turbulent flow has been one of the most intractable problems of classical physics. (1993): 'In turbulent times an enterprise has to be managed both to withstand sudden blows and to avail itself of sudden unexpected opportunities.'

Instability Widely used in economics, finance, psychology, politics, etc. to suggest potential or real sudden, drastic change

[e.g., Foreign Policy (2009)].

In chemistry, "A stable compound occurs when the total energy of the combination has lower energy than the separated atoms." (http://hyperphysics.phy-astr.gsu.edu/hbase/ chemical/bond.html) In an unstable compound the opposite is true, or the compound is so close to the threshold that a small addition of energy, e.g., an intruding photon, can destabilize it.

In systems theory, an 'unusually or unnaturally large fluctuation that may lead to serious damage or system failure if allowed to continue beyond a certain limit' (businessdictionary.com).

\section{IMPLICATIONS FOR EDUCATORS AND RESEARCHERS}

\section{Educators might consider:}

(1) Emphasizing to students that in the real world, substitution trajectories are not necessarily everywhere differentiable. Nor are they always s-shaped; they may show a series of plateaux. Kicking the product into new growth following each plateau may require quite different managerial and marketing skills. 
(2) Bringing back an emphasis, in strategy classes, on the 'turbulence' ideas of Ansoff and McDonnell (1990) and Drucker (1993).

(3) Jointly presenting mathematical, technological, managerial, and leadership issues connected with periods of extreme industry challenge.

(4) Discussing the social and political contexts, and not just the business and technical details, of these challenges.

With regard to point 1 above, technology management researchers - understanding that the differentiability of e.g. utility functions has been a point of contention for decades between neoclassical and Austrian economists [see, e.g., Caplan (1999)], and that economics is currently criticized for subordinating theoretical accuracy to mathematical tractability - would do well to open a similar dialog in our own discipline. The fact that we have traditionally spoken of 'discontinuous innovations' [e.g., Funk (2008)] makes this an overdue imperative.

Clearly,

- Not all business or social phenomena strictly correspond to the hard-sciences phenomena with which they share a name.

- Colloquial usages maintain legitimacy even when a word has a rigorous scientific meaning.

- Different research disciplines, whether hard or soft, may give different meanings to the same term.

- Researchers cannot control the terms appropriated by popular writers.

Nonetheless researchers are obliged to exercise care in nomenclature, not bending these four truths too far out of shape.

\section{FURTHER MANAGERIAL AND SUSTAINABILITY IMPLICATIONS}

Revitalizations, as is well known, may succeed or fail. Though the structural similarity of revitalization and substitution have been noted in passing elsewhere, we have made it explicit here, as it implies that chaos may arise in managerial situations more frequently than has been realised before now. This is a clear implication of Grove's book, and is consistent with the Modis and Debecker (1992) results and Sood and Tellis' (2004) finding that frequent revitalization attempts are the norm in technology markets.

The revitalization campaign depicted in Figure 4 reflects management's deliberate variation of a diffusion parameter, that is, a renewed advertising push. The research shows that this parameter variation can induce chaos or Modis and Debecker (1992) volatility. Where managers have, prior to now, expected either sales growth or no incremental growth as a result of revitaliza-

Journal of Technology Management for Growing Economies, Volume 7, Number 1, April 2016
Inflection Points and Industry

Change 
Phillips $\dagger$, F. Hwang, G. G. Limprayoon $\uparrow, P$.

tion, it is now clear that a revitalization attempt can lead to puzzling fluctuations.

It is possible that continuous monitoring of data can help managers distinguish among the three kinds of transition points discussed in this paper. The importance of the daily sales report is reinforced.

Volatility is abhorred by marketing VPs and operations managers, but tolerated by finance professionals. Marketers and strategists should find ways to respond to the inevitable role of chaos and quasi-chaos in the sales cycle. Part of this response lies in not killing a product too soon; what appears to be chaotic fluctuation may be just transitory volatility. Patience appears to be a virtue.

Most important from a managerial perspective is Modis and Debecker's (1992) implication that 'The generalised picture is one of alternating states of logistic growth and chaos'. The managerial styles appropriate for each regime differ markedly. Though Only the Paranoid Survive is a title that sells books, it could well be true that in stable times the skilled administrator survives; when chaos is on the horizon the alert, visionary, experienced manager survives; and when chaos has hit, the steadfast, inspirational leader represents the enterprise' best chance of survival.

In current US practice, executives are tagged as entrepreneurial managers, administrators, or turnaround experts, and steered into the situations where their respective skills are most needed. The results of this paper suggest that these categories almost, but not quite, match the environmental regimes under which technology businesses can expect to operate, and that the categories/ career tracks might well be re-examined.

\section{ENDNOTES}

1. The quotation refers to Grove (1996a). See also Grove (1996b, 1999).

2. See Phillips (2001) for development of these details of product revitalization. The original concept is due to Levitt (1965).

3. The 'crossing the chasm' phrase is due to Moore (2002), which introduced the venerable product life cycle concept to technology marketers. Evidence that the cycle is not smoothly bell-shaped but rather a series of plateaux, is due to Loch and Huberman (1999) and later to Sood and Tellis (2004).

\section{REFERENCES}

Ansoff, I. and McDonnell, E. (1990), 'Implanting Strategic Management' (2nd Ed)., USA. Prentice Hall PTR.

Australian Academy of Science (2006) 'A quiet revolution - the science of complex systems', (online), (cited 24 April 2010). Available from http://www.science.org.au/nova/094/094key. htm

Ausubel, J.H., Grüler, A., and Nakicenovic, N. (1988) 'Carbon dioxide emissions in a methane economy’, Climatic Change, XII, 3, pp. 245-263. http://dx.doi.org/ 10.1007/BF00139432.

Journal of Technology Management for Growing Economies, Volume 7, Number 1, April 2016 
Bass, F.M. (1969) 'A new product growth model for consumer durables', Management Science, XV, 5, pp. 215-227. http://dx.doi.org/10.1287/mnsc.15.5.215.

Brinker, S. (2008) 'A new s curve for search engine ads?' Chief Marketing Technologist Blog, (online) (cited 6 April 2010). Available from http://www.chiefmartec.com/2008/04/a-news-curve-f.html

Boswijk, H.P. and Franses, P.H. (2005) 'On the Econometrics of the Bass Diffusion Model', Journal of Business \& Economic Statistics, XXIII, 3, pp. 255-268. http://dx.doi. org/10.1198/073500104000000604

Caplan, B. (1999) 'The Austrian Search for Realistic Foundations', Southern Economic Journal, LXV, 4, pp. 823-838.

Christensen, C.M. (1998), 'The Innovator's Dilemma', HarperBusiness Essentials.

Dimov, S., Hines, P., Naim, M., Wong, H., Bigot, S., and Dorrington, P. (2008) 'Work module 5: Technological Forecasting', Technology Management for Emerging and Disruptive Manufacturing Technologies, Cardiff University (online) (cited 25 October 2010). Available from http://www.cuimrc.cf.ac.uk/node/226

Drucker, P. (1968), 'The Age of Discontinuity', Harpercollins.

Drucker, P. (1993), 'Managing in Turbulent Times', Harper Paperbacks.

Fisher, J., and Pry, R. (1971) 'A simple substitution model of technological change', Technological Forecasting and Social Change, III, pp. 75-88. http://dx.doi.org/10.1016/S0040-1625(71)80005-7.

Foreign Policy, (2009) 'The Axis of Upheaval: A special report on the coming age of instability', Foreign Policy, April, pp. 56-81.

Fourt, L.A., and Woodlock, J.W. (1960) 'Early prediction of market success for new grocery products', Journal of Marketing, XXV, 2, pp. 31-38.

Funk, J.L. (2008) 'Components, systems and technological discontinuities: Lessons from the IT sector', Long Range Planning, XLI, 5, pp. 555-573.

Gladwell, M. (2000), 'The Tipping Point: How Little Things Can Make a Big Difference’, London. Abacus.

Grove, A.S. (1996a), 'Only the paranoid survive: How to exploit the crisis points that challenge every company and career, New York. Currency Doubleday.

Grove, A.S. (1996b) 'Only the paranoid survive: Book preface', (online) (cited 1 March 2009). Available from <URL: http://www.intel.com/pressroom/kits/bios/grove/paranoid.htm>

Grove, A.S. (1999) 'Global executive: Intel's Andrew Grove on competitiveness', The Academy of Management Executive, XIII, 1, pp. 15-24.

Jonas, W. (2005), 'Mosby's Dictionary of Complementary and Alternative Medicine', (1st Ed)., Elsevier. http://dx.doi.org/10.1089/acm.2005.11.739.

Kaplan, S., Murray, F., and Henderson, R. (2003) 'Discontinuities and senior management: assessing the role of recognition in pharmaceutical firm response to biotechnology', Industrial and Corporate Change, XII, 2, pp. 203-233. http://dx.doi.org/ 10.1093/icc/12.2.203.

Kelly, K. (1995), 'Out of control: The new biology of machines, social systems, \& the economic world', (Reprint Ed)., New York. Basic Books.

Laakso, K., \& Palomäki, J. (2013). The importance of a common understanding in emergency management. Technological Forecasting and Social Change, 80(9), 1703-1713. http:// dx.doi.org/10.1016/j.techfore.2012.12.012.

Levitt, T. (1965) 'Exploit the Product Life Cycle', Harvard Business Review, XLIII, 6, pp. 81-94.

Linstone, H.A. (1999) 'Complexity science: Implications for forecasting', Technological Forecasting and Social Change, LXII, 1-2, pp. 79-90.

Loch, C. H., \& Huberman, B. a. (1999). A Punctuated-Equilibrium Model of Technology Diffusion. Management Science, 45(2), 160-177. http://dx.doi.org/10.1287/mnsc.45.2.160

Modis, T. (2002) Forecasting the growth of complexity and change', Technological Forecasting and Social Change, LXIX, 2, pp. 377-404.

Modis, T., and Debecker, A. (1992) 'Chaos-like states can be expected before and after logistic
Inflection Points and Industry Change

Journal of Technology Management for Growing Economies, Volume 7, Number 1, April 2016 
Phillips†, F. Hwang, G. G. Limprayoon $\dagger$, P. growth', Technological Forecasting and Social Change, XLII, 2, pp. 111-120.

Moin, P., and Kim, J. (1997) 'Tackling Turbulence with Supercomputers', Scientific American, CCLXXVI, 1, pp. 62-68.

Moore, G.A. (2002), 'Crossing the chasm: Marketing and selling disruptive products to mainstream customers' (rev. Ed.), New York. HarperBusiness.

National Science Foundation Advisory committee for Environmental Research and Education (2009) 'Transitions and Tipping Points in Complex Environmental Systems' (online) (cited 24 April 2010). Available from www.nsf.gov/geo/ere/ereweb/ac-ere/nsf6895_ere report_090809.pdf.

Phillips, F. (1985) 'Advanced DSS design in consumer and marketing research', DSS'85: Fifth International Conference on Decision Support Systems. Anthologised in Decision Support Systems: Putting Theory into Practice, eds. Sprague, R., and H. Watson, 1986, Eaglewood Cliffs: Prentice-Hall.

Phillips, F. (2001), 'Market-oriented technology management: Innovating for profit in entrepreneurial times', Heidelberg. Springer Verlag.

Phillips, F. (2007) 'On s-curves and tipping points', Technological Forecasting and Social Change, LXXIV, 6, p. 715-730.

Phillips, F., and Kim, N. (1996) 'Implications of chaos research for new product forecasting', Technological Forecasting and Social Change, LIII, 3, pp. 239-261.

Phillips, F., and Su, Y.-S. (2009) 'Chaos, strategy, and action: How not to fiddle while Rome burns', International Journal of Innovation and Technology Management. Vol.10, No. 6, pp.1-19, December.

Prigogine, I., (1984), 'Order Out of Chaos', Bantam.

Rai, A., Ravichandran, T., \& Samaddar, S. (1998). Global Diffusion. Communications of the ACM, 41(10), 97-106.

Ruppel, A. (1997) 'Reflections on Inflections', Decision Line, 28, 01, (online) (cited 19 April 2009). Available from http://www.decisionsciences.org/decisionline/VOL28/28_1/books. htm.

Seet, S.P. (2005) 'Managing in Turbulent Environments: Igor Ansoff's Strategic Success Model', Singapore Institute of Management, Management News, (online) (cited 24 April 2010). Available from <URL: http://www.ansoffasia.com/article002.pdf $>$

Smith, K.A. (2009) 'Only the Paranoid Survive: How to Exploit the Crisis Point That Challenge Every Company and Career', Journal of Engineering Education, (online) (cited 19 April 2009). Available from http://findarticles.com/p/articles/mi qa3886/is 199904/ai n8835656/

Sood, A.J., and Tellis, G.J. (2004) 'The s-curve of technological evolution: strategic law or selffulfilling prophecy?', Marketing Science Institute Working Paper, (online) (cited 20 April 2009). Available from <URL: http://www.msi.org/publications/publication.cfm?pub=700>

Wolfram, S. (2002), ‘A New Kind of Science’ (1st Ed.), Wolfram Media. 